\title{
Magnetic Rayleigh-Bénard Convection of Air in a Coaxial Double Cylinder
}

\author{
Toshio TAGAWA ${ }^{* 1}$ \\ *1 Tokyo Metropolitan Univ. Dept. of Aerospace Engineering, \\ Asahigaoka 6-6, Hino, Tokyo, 191-0065 Japan
}

\begin{abstract}
Linear stability analyses and numerical computations have been carried out for a magnetic Rayleigh-Bénard convection of air in a coaxial double cylinder in the absence of gravity field. An inner cylinder is heated and an outer cylinder is cooled both isothermally. The air filled within the gap of double cylinder is unstable under certain strength of the applied toroidal magnetic field since the heated air is repelled radially outward due to the magnetic buoyancy force. The stability analysis quantitatively predicts the critical values for the onset of thermal convection for various values of the radius ratio.
\end{abstract}

Key Words : Paramagnetic Gas, Buoyant Convection, Linear Stability Analysis

\section{1. 緒言}

近年，超伝導電磁石が商品化されたことから，数テスラから 15 テスラ程度の強磁場が比較的容易に利用できる 状況にある. 電磁流体力学の分野では, 以前は導電性流体のみが研究対象であったのに対し, 最近では空気や水の ような非導電性流体まで研究範囲が広がっており, それはこれまで無視されてきた磁気体積力（単に磁気力，ある いは磁化力とも呼ばれる）に起因するものである. これまでの普通の電磁石が発生する磁束密度を 0.1 テスラ程度 とすると, 超伝導電磁石のそれは 100 倍のオーダーであり, 二乗に比例する磁気エネルギーに換算すると 1 万倍に なる.これは鉄などの強磁性材料に比べて, 磁化率が非常に小さいとされる空気や水においてさえ, 磁気力が重力 に匹敵するほどに顕在化することを意味する. この磁気力は, 分子レベルで作用し, 磁化率と磁場の 2 乗の勾配に 比例する（後で登場する式(3)で与えられる）。単相で温度や濃度の勾配がない状況下においては, この磁気力はポ テンシャルを持つので, 重力とよく似ている. その一方, 磁化率の正負に応じて, 引力と斥力の両方が作用すると いう点で, 重力とは異なる部分もある. このように磁気力は, 重力と同様, 保存力になりうる性質に加え, 斥力も 使えることから, 温度や濃度に起因する自然対流や二相流の熱流動制御問題に関連して, 学術的に非常に興味深い.

水は反磁性流体の代表的なものであり，その磁化率は負であり，磁場から反発される性質を持つ，一方で空気は 常磁性流体の代表的なものであり, 磁化率が正であるため磁場から引力を受ける. 空気は単体ではなく窒素や酸素 などの混合物であるが, 窒素が普通の反磁生流体であるのに対し, 酸素が例外的に大きな值を持つ常磁性流体であ るため, 混合物としての空気は常磁性流体である. 例えば二相流の一例として, 空気中に存在する水滴に対して, 超伝導電磁石を用いて磁場勾配が上向きに小さくなって行くように与えると, 水滴は上向きの磁気反発力を受け, 下向きの重力と釣り合い浮遊する. この時, 周囲空気は下向きの磁気引力を受けるので, 結果として磁気浮力が作 用する. 雾囲気を常圧空気から高圧酸素などにしてやれば, この磁気浮力がより顕在化するので, 水滴はさらに浮 上し易くなる ${ }^{(1)}$.

次に磁化率の温度依存性に起因寸る現象の一例として, 磁気熱対流を挙げる. 一般に反磁性流体の磁化率は温度 依存しないが，常磁性流体のそれは温度に反比例することが, Curie の法則として知られている.このことは, 空気

\footnotetext{
*原稿受付 2010 年 9 月 14 日

*1正員, 首都大学東京大学院システムデザイン研究科（†191-0065 東京都日野市旭が丘 6-6）

E-mail: ttagawa@cc.tmit.jp
} 
のような常磁性流体を加熱すると磁化率が下がるため, 磁場に引き付けられる性質が弱まり, 結果として相対的に 高温部分の常磁性流体は磁場から反発されることになる. それは重力場における熱対流との対比で考えれば, 加熱 された流体が軽くなって上昇するのに対応している.

さて, 重力場における水平流体層の熱対流の安定性は，Rayleigh-Bénard問題として良く知られている(2). Rayleigh の理論的研究に先立って, Bénardが行った実験では, 上面が自由表面である場合を扱っているので, 浮力による影 響のみならず，薄い流体層であるので界面張力による影響がより重要な役割を果たす，そのようなマランゴニ対流 や浮力対流の線形安定性解析, さらにはそれらの複合効果については, 日向野 ${ }^{(3,4,5)}$ によって詳しく研究されている. その三連報の論文では, 境界条件が固定端か自由端かどうかの議論に加え, 熱的境界条件としてBiot数を用いて一 般化され，対流発生限界式を与えている．しかしながら，このような線形安定性理論の磁気熱対流への試みは今の ところ皆無と思われる，そこで本研究では，同軸二重円管内における空気の磁気Rayleigh-Bénard対流を想定し，線 形安定性解析と差分法による数值計算を実施し，さらに両者を比較検討し考察する.

\section{2. 記号}

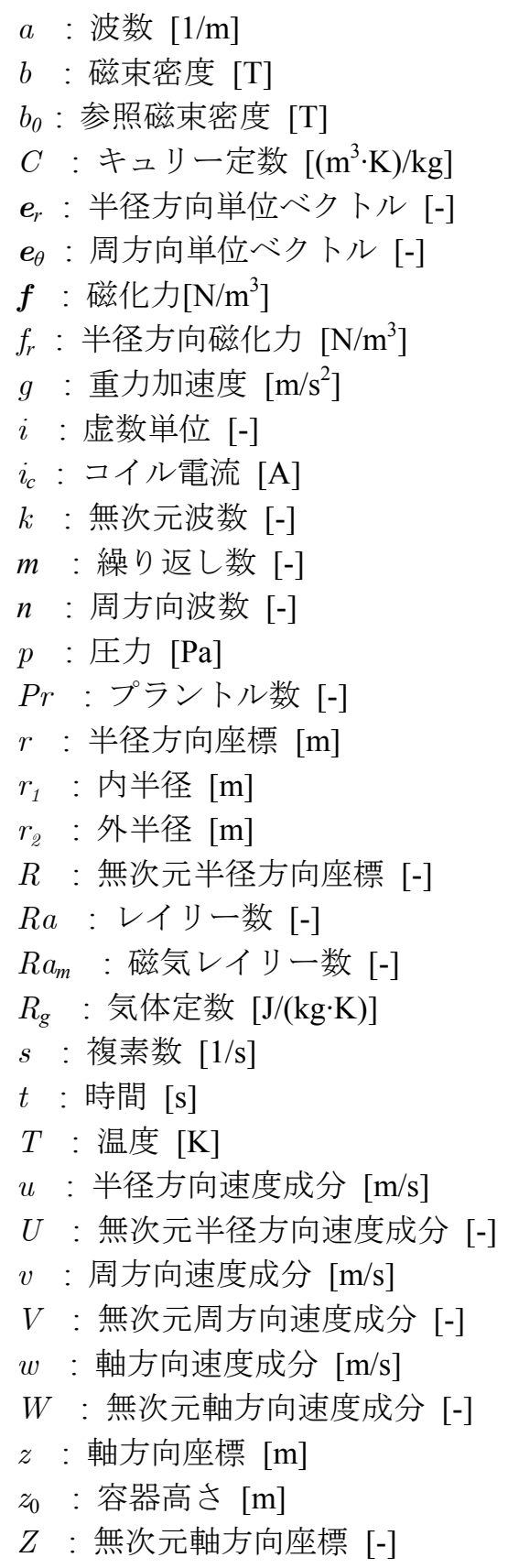




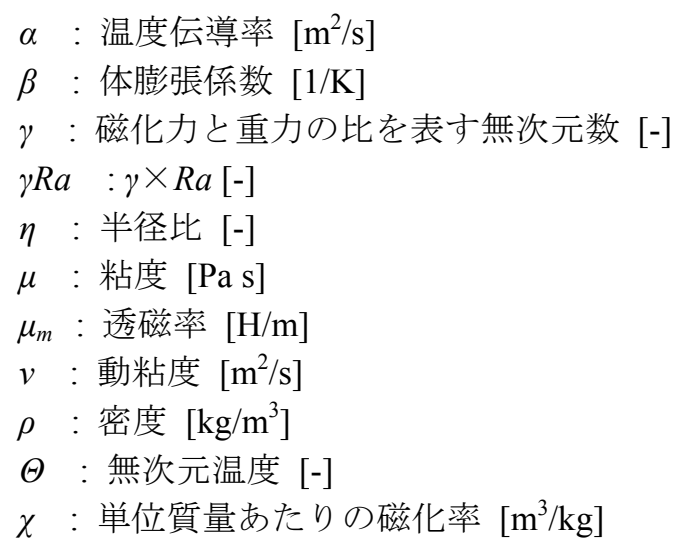

添え字：

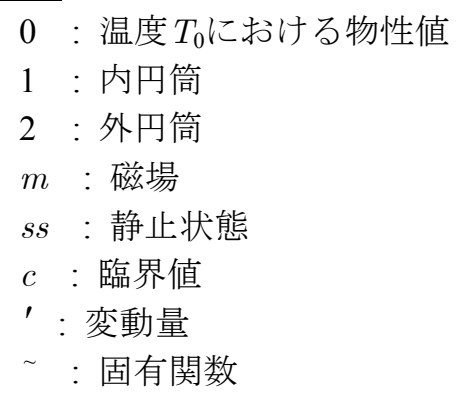

\section{3. 支配方程式}

本研究で想定した解析モデルを説明する. 無重力場中に置かれた同軸の二重円筒容器を考え, 中心軸上の無限に 長い直線コイルに一定值の電流が流れている．この電流が作る磁場は周方向成分のみを持ち，軸から離れるにつれ て弱くなる. 二重円筒間の流体は，常磁性流体の空気を想定し，内円筒を等温加熱，外円筒を等温冷却し，ある臨 界值を超えると対流が発生する．それは，温度の高い部分の流体は磁場から反発され，一方で温度の低い部分の流 体は磁場の強い部分に引き寄せられるという不安定性に起因寸る ${ }^{(6)}$. 本研究では, 外円筒に対する内円筒の半径比 を種々変えて解析を行い，代表長さは二重円筒の隙間幅とする. 以下，基礎式を導出する. 三次元円筒座標系にお ける半径方向の運動方程式は, 次のように書ける.

$$
\rho\left(\frac{\partial u}{\partial t}+u \frac{\partial u}{\partial r}+\frac{v}{r} \frac{\partial u}{\partial \theta}-\frac{v^{2}}{r}+w \frac{\partial u}{\partial z}\right)=-\frac{\partial p}{\partial r}+\mu\left(\frac{\partial^{2} u}{\partial r^{2}}+\frac{1}{r} \frac{\partial u}{\partial r}-\frac{u}{r^{2}}+\frac{1}{r^{2}} \frac{\partial^{2} u}{\partial \theta^{2}}-\frac{2}{r^{2}} \frac{\partial v}{\partial \theta}+\frac{\partial^{2} u}{\partial z^{2}}\right)+f_{r}
$$

次に，無限直線コイルに流れる電流を $i_{c}$ とすれば，発生する磁束密度分布はAmpèreの法則から求められ，今の場 合それは周方向成分だけである.

$$
\vec{b}=\left(\frac{\mu_{m} i_{c}}{2 \pi r}\right) \vec{e}_{\theta}
$$

ここで，磁化力は，流体の磁化率と磁場勾配に関係し，近似的に次式で与えられる ${ }^{(6,7)}$.

$$
\vec{f}=\frac{\rho \chi}{2 \mu_{m}} \vec{\nabla}(\vec{b} \cdot \vec{b})
$$

(2)(3)から, 次式のように磁化力は半径方向に働くことがわかる.

$$
\vec{f}=-\frac{\rho \chi \mu_{m} i_{c}^{2}}{4 \pi^{2}} \frac{1}{r^{3}} \vec{e}_{r}
$$

次にBoussinesq近似を考える. 流体が，ある均一温度 $T_{0}$ にるときは刘流が発生しないので，半径方向の運動 方程式において磁化力と圧力勾配が釣り合って,

$$
0=-\frac{\partial p_{0}}{\partial r}-\frac{\rho_{0} \chi_{0} \mu_{m} i_{c}^{2}}{4 \pi^{2}} \frac{1}{r^{3}}
$$


を得る.ここで, 密度 $\rho$ と磁化率 $\chi$ にかかる下付添え字 0 は温度 $T_{0}$ における物性值を示す. (1) と(5)の差をとると次 式を得る.

$$
\rho\left(\frac{\partial u}{\partial t}+u \frac{\partial u}{\partial r}+\frac{v}{r} \frac{\partial u}{\partial \theta}-\frac{v^{2}}{r}+w \frac{\partial u}{\partial z}\right)=-\frac{\partial\left(p-p_{0}\right)}{\partial r}+\mu\left(\frac{\partial^{2} u}{\partial r^{2}}+\frac{1}{r} \frac{\partial u}{\partial r}-\frac{u}{r^{2}}+\frac{1}{r^{2}} \frac{\partial^{2} u}{\partial \theta^{2}}-\frac{2}{r^{2}} \frac{\partial v}{\partial \theta}+\frac{\partial^{2} u}{\partial z^{2}}\right)-\left(\rho \chi-\rho_{0} \chi_{0}\right) \frac{\mu_{m} i_{c}{ }^{2}}{4 \pi^{2} r^{3}}
$$

体膨張係数の定義

$$
\beta=-(\partial \rho / \partial T) / \rho
$$

を考慮し，さらに理想気体

$$
\rho=p /\left(R_{g} T\right)
$$

であると仮定できるとき，密度の温度変化は近似的に次式で与えられる.

$$
\rho-\rho_{0} \cong(\partial \rho / \partial T)_{0}\left(T-T_{0}\right)=-\rho_{0} \beta_{0}\left(T-T_{0}\right)=-\rho_{0}\left(T-T_{0}\right) / T_{0}
$$

一方，空気のような常磁性流体に対しては Curie の法則

$$
\chi=C / T
$$

を考慮し，磁化率の温度変化は，密度と同じようにして，次式を得る．

$$
\chi-\chi_{0} \cong(\partial \chi / \partial T)_{0}\left(T-T_{0}\right)=-\left(C / T_{0}^{2}\right)\left(T-T_{0}\right)=-\chi_{0}\left(T-T_{0}\right) / T_{0}
$$

したがって，(6)式の右辺第 2 項は

$$
\begin{aligned}
\rho \chi-\rho_{0} \chi_{0} & \cong\{\partial(\rho \chi) / \partial T\}_{0}\left(T-T_{0}\right)=\left\{\rho_{0}(\partial \chi / \partial T)_{0}+\chi_{0}(\partial \rho / \partial T)_{0}\right\}\left(T-T_{0}\right) \\
& =-2 \rho_{0} \chi_{0}\left(T-T_{0}\right) / T_{0}=-2 \rho_{0} \chi_{0} \beta\left(T-T_{0}\right)
\end{aligned}
$$

この(12)式は，空気や酸素ガスのような常磁性流体の場合にのみ利用できる. 結局, 運動方程式の半径方向成分 は, 変動圧力を $p$ と書き直し, 以下のように書ける.

$$
\frac{\partial u}{\partial t}+u \frac{\partial u}{\partial r}+\frac{v}{r} \frac{\partial u}{\partial \theta}-\frac{v^{2}}{r}+w \frac{\partial u}{\partial z}=-\frac{1}{\rho_{0}} \frac{\partial p}{\partial r}+v\left(\frac{\partial^{2} u}{\partial r^{2}}+\frac{1}{r} \frac{\partial u}{\partial r}-\frac{u}{r^{2}}+\frac{1}{r^{2}} \frac{\partial^{2} u}{\partial \theta^{2}}-\frac{2}{r^{2}} \frac{\partial v}{\partial \theta}+\frac{\partial^{2} u}{\partial z^{2}}\right)+\chi_{0} \beta\left(T-T_{0}\right) \frac{\mu_{m} i_{c}{ }^{2}}{2 \pi^{2} r^{3}}
$$

ここで, $v\left(=\mu / \rho_{0}\right)$ は動粘度である，その他の解析に必要な方程式は，次式の通りである.

$$
\begin{aligned}
& \frac{\partial v}{\partial t}+u \frac{\partial v}{\partial r}+\frac{v}{r} \frac{\partial v}{\partial \theta}+\frac{u v}{r}+w \frac{\partial v}{\partial z}=-\frac{1}{\rho_{0}} \frac{1}{r} \frac{\partial p}{\partial \theta}+v\left(\frac{\partial^{2} v}{\partial r^{2}}+\frac{1}{r} \frac{\partial v}{\partial r}-\frac{v}{r^{2}}+\frac{1}{r^{2}} \frac{\partial^{2} v}{\partial \theta^{2}}+\frac{2}{r^{2}} \frac{\partial u}{\partial \theta}+\frac{\partial^{2} v}{\partial z^{2}}\right) \\
& \frac{\partial w}{\partial t}+u \frac{\partial w}{\partial r}+\frac{v}{r} \frac{\partial w}{\partial \theta}+w \frac{\partial w}{\partial z}=-\frac{1}{\rho_{0}} \frac{\partial p}{\partial z}+v\left(\frac{\partial^{2} w}{\partial r^{2}}+\frac{1}{r} \frac{\partial w}{\partial r}+\frac{1}{r^{2}} \frac{\partial^{2} w}{\partial \theta^{2}}+\frac{\partial^{2} w}{\partial z^{2}}\right) \\
& \frac{\partial u}{\partial r}+\frac{u}{r}+\frac{1}{r} \frac{\partial v}{\partial \theta}+\frac{\partial w}{\partial z}=0 \\
& \frac{\partial T}{\partial t}+u \frac{\partial T}{\partial r}+\frac{v}{r} \frac{\partial T}{\partial \theta}+w \frac{\partial T}{\partial z}=\alpha\left(\frac{\partial^{2} T}{\partial r^{2}}+\frac{1}{r} \frac{\partial T}{\partial r}+\frac{1}{r^{2}} \frac{\partial^{2} T}{\partial \theta^{2}}+\frac{\partial^{2} T}{\partial z^{2}}\right)
\end{aligned}
$$

\section{4. 線形安定性解析}

基本流は静止状態であり，温度場は熱伝導状態である.

$$
T_{s s}(r)=\frac{T_{1} \ln \left(r / r_{2}\right)-T_{2} \ln \left(r / r_{1}\right)}{\ln \left(r_{1} / r_{2}\right)}
$$

このとき半径方向の運動方程式の釣り合いは静止状態の圧力を用いて，次式で与えられる. 


$$
0=-\frac{1}{\rho_{0}} \frac{\partial p_{s s}}{\partial r}+\frac{\mu_{m} i_{c}^{2} \chi_{0} \beta}{2 \pi^{2}}\left(T_{s s}(r)-T_{0}\right) \frac{1}{r^{3}}
$$

次に, この基本状態からの恋動分を

$$
u=u^{\prime}(r, \theta, z, t), \quad v=v^{\prime}(r, \theta, z, t), \quad w=w^{\prime}(r, \theta, z, t), \quad p=p_{s s}(r)+p^{\prime}(r, \theta, z, t), \quad T=T_{s s}(r)+T^{\prime}(r, \theta, z, t)
$$

と置き, 元の式(13)-(17)を線形化し, 以下の式を得る.

$$
\begin{aligned}
& \frac{\partial u^{\prime}}{\partial t}=-\frac{1}{\rho_{0}} \frac{\partial p^{\prime}}{\partial r}+v\left(\frac{\partial^{2} u^{\prime}}{\partial r^{2}}+\frac{1}{r} \frac{\partial u^{\prime}}{\partial r}-\frac{u^{\prime}}{r^{2}}+\frac{1}{r^{2}} \frac{\partial^{2} u^{\prime}}{\partial \theta^{2}}-\frac{2}{r^{2}} \frac{\partial v^{\prime}}{\partial \theta}+\frac{\partial^{2} u^{\prime}}{\partial z^{2}}\right)+\frac{\mu_{m} i_{c}^{2} \chi_{0} \beta}{2 \pi^{2}} \frac{T^{\prime}}{r^{3}} \\
& \frac{\partial v^{\prime}}{\partial t}=-\frac{1}{\rho_{0}} \frac{1}{r} \frac{\partial p^{\prime}}{\partial \theta}+v\left(\frac{\partial^{2} v^{\prime}}{\partial r^{2}}+\frac{1}{r} \frac{\partial v^{\prime}}{\partial r}-\frac{v^{\prime}}{r^{2}}+\frac{1}{r^{2}} \frac{\partial^{2} v^{\prime}}{\partial \theta^{2}}+\frac{2}{r^{2}} \frac{\partial u^{\prime}}{\partial \theta}+\frac{\partial^{2} v^{\prime}}{\partial z^{2}}\right) \\
& \frac{\partial w^{\prime}}{\partial t}=-\frac{1}{\rho_{0}} \frac{\partial p^{\prime}}{\partial z}+v\left(\frac{\partial^{2} w^{\prime}}{\partial r^{2}}+\frac{1}{r} \frac{\partial w^{\prime}}{\partial r}+\frac{1}{r^{2}} \frac{\partial^{2} w^{\prime}}{\partial \theta^{2}}+\frac{\partial^{2} w^{\prime}}{\partial z^{2}}\right) \\
& \frac{\partial u^{\prime}}{\partial r}+\frac{u^{\prime}}{r}+\frac{1}{r} \frac{\partial v^{\prime}}{\partial \theta}+\frac{\partial w^{\prime}}{\partial z}=0 \\
& \frac{\partial T^{\prime}}{\partial t}+u^{\prime} \frac{T_{1}-T_{2}}{\ln \left(r_{1} / r_{2}\right)} \frac{1}{r}=\alpha\left(\frac{\partial^{2} T^{\prime}}{\partial r^{2}}+\frac{1}{r} \frac{\partial T^{\prime}}{\partial r}+\frac{1}{r^{2}} \frac{\partial^{2} T^{\prime}}{\partial \theta^{2}}+\frac{\partial^{2} T^{\prime}}{\partial z^{2}}\right)
\end{aligned}
$$

さらに変動量を以下のように置く.

$$
\left\{\begin{array}{l}
u^{\prime}(r, \theta, z, t)=\tilde{u}(r) \exp \{i(n \theta+a z)+s t\} \\
v^{\prime}(r, \theta, z, t)=\tilde{v}(r) \exp \{i(n \theta+a z)+s t\} \\
w^{\prime}(r, \theta, z, t)=\tilde{w}(r) \exp \{i(n \theta+a z)+s t\} \\
p^{\prime}(r, \theta, z, t)=\tilde{p}(r) \exp \{i(n \theta+a z)+s t\} \\
T^{\prime}(r, \theta, z, t)=\tilde{T}(r) \exp \{i(n \theta+a z)+s t\}
\end{array}\right.
$$

ここで, $n$ は周方向波数であり整数, $a$ は軸方向波数であり実数, $s$ は時定数であり複素数である.

\section{$4 \cdot 1$ 軸対称擋乱}

軸対称でかつ周方向速度の変動波数を無視する. (21), (23), (24), (25)からそれぞれ次式を得る.

$$
\begin{aligned}
& s \tilde{u}=-\frac{1}{\rho_{0}} \frac{d \tilde{p}}{d r}+v\left(\frac{d^{2} \tilde{u}}{d r^{2}}+\frac{1}{r} \frac{d \tilde{u}}{d r}-\frac{\tilde{u}}{r^{2}}-a^{2} \tilde{u}\right)+\frac{\mu_{m} i_{c}^{2} \chi_{0} \beta}{2 \pi^{2}} \frac{\tilde{T}}{r^{3}} \\
& s \tilde{w}=-\frac{1}{\rho_{0}} i a \tilde{p}+v\left(\frac{d^{2} \tilde{w}}{d r^{2}}+\frac{1}{r} \frac{d \tilde{w}}{d r}-a^{2} \tilde{w}\right) \\
& \frac{d \tilde{u}}{d r}+\frac{\tilde{u}}{r}+i a \tilde{w}=0 \\
& s \tilde{T}=\alpha\left(\frac{d^{2} \tilde{T}}{d r^{2}}+\frac{1}{r} \frac{d \tilde{T}}{d r}-a^{2} \tilde{T}\right)-\frac{T_{1}-T_{2}}{\ln \left(r_{1} / r_{2}\right)} \frac{\tilde{u}}{r}
\end{aligned}
$$

(28), (29)から虚数単位を消去し，

$$
0=-\frac{1}{\rho_{0}} \tilde{p}+\frac{v}{a^{2}}\left(\frac{d^{2}}{d r^{2}}+\frac{1}{r} \frac{d}{d r}-a^{2}-\frac{s}{v}\right)\left(\frac{d \tilde{u}}{d r}+\frac{\tilde{u}}{r}\right)
$$


さらに，(27),(31)から圧力を消去すると次式を得る.

$$
\frac{v}{a^{2}}\left(\frac{d^{2}}{d r^{2}}+\frac{1}{r} \frac{d}{d r}-\frac{1}{r^{2}}-a^{2}-\frac{s}{v}\right)\left(\frac{d^{2}}{d r^{2}}+\frac{1}{r} \frac{d}{d r}-\frac{1}{r^{2}}-a^{2}\right) \tilde{u}=\frac{\mu_{m} i_{c}^{2} \chi_{0} \beta}{2 \pi^{2}} \frac{\tilde{T}}{r^{3}}
$$

一方，(30)は整理されて, 次式を得る.

$$
\alpha\left(\frac{d^{2}}{d r^{2}}+\frac{1}{r} \frac{d}{d r}-a^{2}-\frac{s}{\alpha}\right) \tilde{T}=\frac{T_{1}-T_{2}}{\ln \left(r_{1} / r_{2}\right)} \frac{\tilde{u}}{r}
$$

境界条件は，内円筒，外円筒とも滑り無し条件である.

$$
\tilde{u}=d \tilde{u} / d r=\tilde{T}=0 \quad \text { at } \quad r=r_{1}, r_{2}
$$

これら(32), (33)および境界条件(34)が対流発生の臨界值を決める方程式である. 日向野(2)によれば，「複素数 実部 $s_{\mathrm{r}}$, 虚部を $s_{\mathrm{i}}$ と置くとき, $s=s_{\mathrm{r}}+i s_{\mathrm{i}}$ と書かれ, $s=0$ は $s_{\mathrm{r}}=s_{\mathrm{i}}=0$ を与え, これは変動が時間の指数関数で減少 も増大もしない限界，あるいは中立安定（Marginal あるいはNeutral Stability）状態にあり，生じた対流は定常流 であることを意味する」とある. 本研究では, 安定性の交換原理が成り立つものとし ${ }^{2}=0$ とし, 無次元化すると 次式を得る。

$$
\begin{aligned}
& \left(\frac{d^{2}}{d R^{2}}+\frac{1}{R} \frac{d}{d R}-\frac{1}{R^{2}}-k^{2}\right)^{2} \tilde{U}=k^{2} \frac{\gamma R a}{2 \pi^{2}} \frac{\tilde{\Theta}}{R^{3}} \\
& \left(\frac{d^{2}}{d R^{2}}+\frac{1}{R} \frac{d}{d R}-k^{2}\right) \tilde{\Theta}=\frac{\tilde{U}}{\ln \eta \cdot R}
\end{aligned}
$$

境界条件は，内円筒，外円筒ともに固体壁で一定温度である場合，次式で与えられる．

$$
\tilde{U}=d \tilde{U} / d R=\tilde{\Theta}=0 \quad \text { at } R=R_{1}, R_{2}
$$

ここで, $\gamma R a$ は無重力下の磁気熱対流で現れる無次元数であり, 次式で定義される.また, $k$ は無次元波 数である.

$$
\gamma R a=\frac{\chi_{0} \mu_{m} i_{c}^{2} \beta\left(T_{1}-T_{2}\right)}{\alpha v}=\underbrace{\frac{\chi_{0} \mu_{m} i_{c}{ }^{2}}{g\left(r_{2}-r_{1}\right)^{3}}}_{\gamma} \underbrace{\frac{g \beta\left(T_{1}-T_{2}\right)\left(r_{2}-r_{1}\right)^{3}}{\alpha v}}_{R a}
$$

最後の項の前半 $(\gamma)$ は, 磁気力と重力の比を表す無次元数であり, 後半はレイリー数 $(R a)$ である. 重力場では, これら 2 つ無次元数が独立に現れるが, 無重力場ではこれらの積の形 $(\gamma R a)$ でのみ現 れ, それが正の值（磁化率が正のときは $T_{1}>T_{2}$ ）のとき不安定となる. また半径比は次式で定義される.

$$
\eta=\frac{r_{1}}{r_{2}}
$$

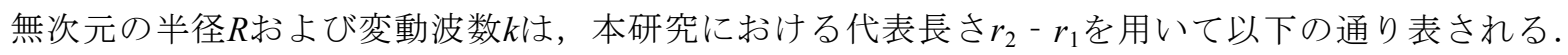

$$
R=\frac{r}{r_{2}-r_{1}}, \quad k=\left(r_{2}-r_{1}\right) a
$$

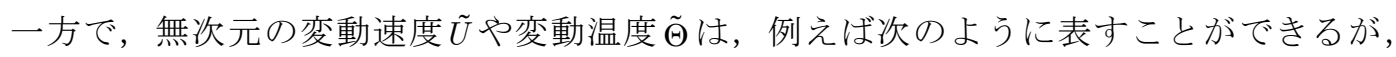

$$
\tilde{U}=\frac{\tilde{u}}{\alpha /\left(r_{2}-r_{1}\right)}, \quad \tilde{\Theta}=\frac{\tilde{T}}{T_{1}-T_{2}}
$$

実際には, 代表温度 $T_{a}$ と代表速度 $u_{a}$ の比が次の関係式

$$
\frac{T_{a}}{u_{a}}=\frac{\left(T_{1}-T_{2}\right)\left(r_{2}-r_{1}\right)}{\alpha}
$$

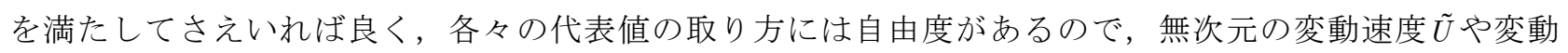
温度 $\tilde{\Theta}$ の絶対值に意味は無い。

\section{$4 \cdot 2$ 平面極擋乱}

軸方向速度の変動波数を無視する。(21), (22), (24), (25)からそれぞれ次式を得る. 


$$
\begin{aligned}
& s \tilde{u}=-\frac{1}{\rho_{0}} \frac{d \tilde{p}}{d r}+v\left(\frac{d^{2} \tilde{u}}{d r^{2}}+\frac{1}{r} \frac{d \tilde{u}}{d r}-\frac{\tilde{u}}{r^{2}}-\frac{n^{2}}{r^{2}} \tilde{u}-i \frac{2 n}{r^{2}} \tilde{v}\right)+\frac{\mu_{m} i_{c}^{2} \chi_{0} \beta}{2 \pi^{2}} \frac{\tilde{T}}{r^{3}} \\
& s \tilde{v}=-\frac{1}{\rho_{0}} \frac{n}{r} i \tilde{p}+v\left(\frac{d^{2} \tilde{v}}{d r^{2}}+\frac{1}{r} \frac{d \tilde{v}}{d r}-\frac{\tilde{v}}{r^{2}}-\frac{n^{2}}{r^{2}} \tilde{v}+i \frac{2 n}{r^{2}} \tilde{u}\right) \\
& \tilde{v}=i \frac{r}{n}\left(\frac{d \tilde{u}}{d r}+\frac{\tilde{u}}{r}\right) \\
& s \tilde{T}=\alpha\left(\frac{d^{2} \tilde{T}}{d r^{2}}+\frac{1}{r} \frac{d \tilde{T}}{d r}-\frac{n^{2}}{r^{2}} \tilde{T}\right)-\frac{T_{1}-T_{2}}{\ln \left(r_{1} / r_{2}\right)} \frac{\tilde{u}}{r}
\end{aligned}
$$

(43), (44), (45)から虚数単位，周方向の速度成分，および圧力を消去し， $s=0$ とすると，次式を得る.

$$
r^{2} \frac{d^{4} \tilde{u}}{d r^{4}}+6 r \frac{d^{3} \tilde{u}}{d r^{3}}+\left(5-2 n^{2}\right) \frac{d^{2} \tilde{u}}{d r^{2}}-\frac{2 n^{2}+1}{r} \frac{d \tilde{u}}{d r}+\frac{\left(n^{2}-1\right)^{2}}{r^{2}} \tilde{u}=\frac{n^{2}}{v} \frac{\mu_{m} i_{c}^{2} \chi_{0} \beta}{2 \pi^{2}} \frac{\tilde{T}}{r^{3}}
$$

エネルギー式(46)も $s=0$ とすると，

$$
\frac{d^{2} \tilde{T}}{d r^{2}}+\frac{1}{r} \frac{d \tilde{T}}{d r}-\frac{n^{2}}{r^{2}} \tilde{T}=\frac{T_{1}-T_{2}}{\alpha \cdot \ln \left(r_{1} / r_{2}\right)} \frac{\tilde{u}}{r}
$$

結局，無次元式として，次の 2 式を連立して解けば良い.

$$
\begin{aligned}
& \left(\frac{d^{4}}{d R^{4}}+\frac{6}{R} \frac{d^{3}}{d R^{3}}+\frac{5-2 n^{2}}{R^{2}} \frac{d^{2}}{d R^{2}}-\frac{2 n^{2}+1}{R^{3}} \frac{d}{d R}+\frac{\left(n^{2}-1\right)^{2}}{R^{4}}\right) \tilde{U}=n^{2} \frac{\gamma R a}{2 \pi^{2}} \frac{\tilde{\Theta}}{R^{5}} \\
& \left(\frac{d^{2}}{d R^{2}}+\frac{1}{R} \frac{d}{d R}-\frac{n^{2}}{R^{2}}\right) \tilde{\Theta}=\frac{\tilde{U}}{\ln \eta \cdot R}
\end{aligned}
$$

境界条件は，(37)で共通である。

\section{4・3 解析方法および結果}

軸対称解析の場合の式(35), (36), (37)を例に取り示す。式(35)は 4 階の微分方程式であるので,

$$
\frac{d^{2} \tilde{U}}{d R^{2}}=\tilde{F}
$$

と置き，最高次が 2 階の微分方程式に階数を落とし，同時に仮想時間項を導入する.

$$
\frac{\partial \tilde{F}}{\partial \tau}=\frac{\partial^{2} \tilde{F}}{\partial R^{2}}+\frac{2}{R} \frac{\partial \tilde{F}}{\partial R}-\left(\frac{3}{R^{2}}+2 k^{2}\right) \tilde{F}+\left(\frac{3}{R^{3}}-\frac{2 k^{2}}{R}\right) \frac{\partial \tilde{U}}{\partial R}-\left(\frac{3}{R^{4}}-\frac{2 k^{2}}{R^{2}}-k^{4}\right) \tilde{U}-k^{2} \frac{\gamma R a}{2 \pi^{2}} \frac{\tilde{\Theta}}{R^{3}}
$$

式(36), (51)にも仮想時間項を導入する.

$$
\begin{aligned}
& \frac{\partial \tilde{\Theta}}{\partial \tau}=\frac{\partial^{2} \tilde{\Theta}}{\partial R^{2}}+\frac{1}{R} \frac{\partial \tilde{\Theta}}{\partial R}-k^{2} \tilde{\Theta}-\frac{\tilde{U}}{\ln \eta \cdot R} \\
& \frac{\partial \tilde{U}}{\partial \tau}=\frac{\partial^{2} \tilde{U}}{\partial R^{2}}-\tilde{F}
\end{aligned}
$$

基本的には, (52), (53),(54)の連立方程式を四次精度中心差分で離散化し時間発展的に解いた。このとき, 無次元波数 $k$ および無次元数 $\gamma R a$ の值を与えて, もし解（固有関数）が時間的に増幅も減衰もしないな ら，そのときがその $k$ に対応する中立の $\gamma R a$ となる。しかし，そのような偶然は期待できないから，本 研究では, 時間ステップ毎の解の変化 $(\Delta F)$ がゼロに近づくように Newton 法を用いて, 与えた $k$ に対 応する中立の $\gamma R a$ を修正しながら求めた. 


$$
{ }^{m+1}(\gamma R a)={ }^{m}(\gamma R a)-c_{1} \frac{{ }^{m}(\Delta \tilde{F})}{-k^{2} \tilde{\Theta} /\left(2 \pi^{2} R^{3}\right)} \Delta \tau
$$

ここで，左上付添字 $m$ は反復回数を表し， $c_{1}$ は定数である。そのような操作を様々な $k$ と対して行い，そ の中で最小の值をとる $\gamma R a$ の值が臨界 $\gamma R a$ 值となる.

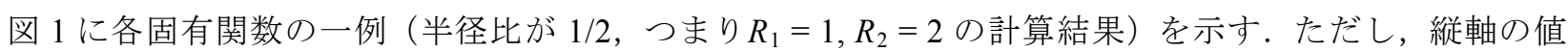
それ自身は意味を持たず，4つの曲線は視覚的にわかりやすくするために，それぞれ拡大率を変えて表

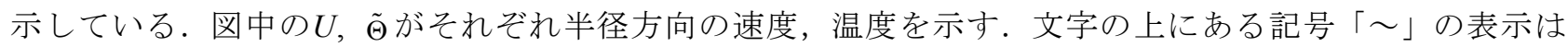

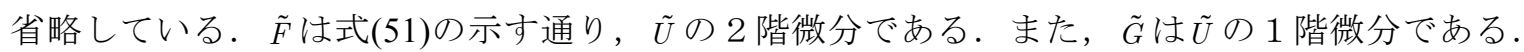

ここで境界条件の与え方の説明に移る. 式(37)では，両境界上で $\tilde{U} も \tilde{G}$ もゼロでなくてはならないこ とを意味する。実際に図 1 ではそれが満足されているのがわかる。 $\tilde{G}$ の微分值である $\tilde{F}$ は両境界におい て非零の值をとっていることから判るように，式(52)を解く際に陽に境界条件を与えることができない. そこで，両固体壁問題の本問題では $\tilde{G} の$ 定積分值は常に零であり，かつ $\tilde{G}$ の両境界上の值が零であるこ とを利用する。つまり，数式では以下のように表される.

$$
\int_{R_{1}}^{R_{2}} \tilde{G}(R) d R=0 \quad \text { and } \quad \tilde{G}\left(R_{1}\right)=\tilde{G}\left(R_{2}\right)=0
$$

その結果， $\tilde{F}$ の定積分值もまた常に零であることがわかる.

$$
\int_{R_{1}}^{R_{2}} \tilde{F}(R) d R=0
$$

本数值解析では, $\tilde{G}$ の積分值を $D$ と置き,

$$
\int_{R_{1}}^{R_{2}} \tilde{G}(R) d R=D
$$

また， $\tilde{F}$ の積分值を $S$ とする。

$$
\int_{R_{1}}^{R_{2}} \tilde{F}(R) d R=S
$$

ただ実際の解析では， $\tilde{F}$ の外壁における值を 0 として固定する代わりに，式(52)中の $\tilde{F}$ を $\tilde{F}-S て ゙$ 代用す ることにより，(57)を満たすようにした。 $\tilde{F}$ の内壁における境界值は，Newton 法により次式を用いて， $D=0$ を満たすように求めた。

$$
{ }^{m+1} \tilde{F}\left(R_{1}\right)={ }^{m} \tilde{F}\left(R_{1}\right)-c_{2} \cdot{ }^{m} D
$$

ここで，左上付き添え字 $m$ は繰り返し回数を表す， $c_{2}$ は定数である。 $D$ も $S$ も計算の開始直後は零からず れているが，収束するにつれて零に近づくことがわかる．なお，本計算では，格子分割数を 100 と， Simpson法により数值積分を行った.

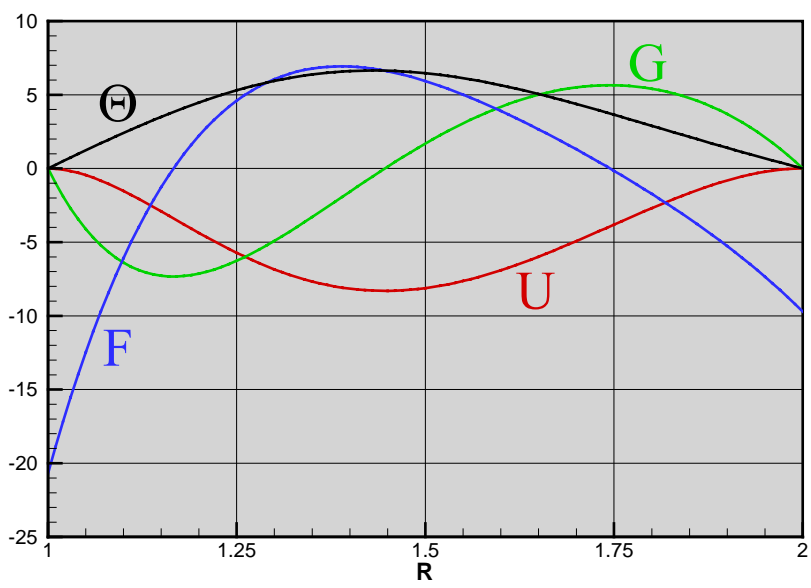

Fig. 1 An example of each eigenfunction for $\eta=1 / 2$ (axisymetric analysis) 
図 2 は，一例として，平面極擋乱の解析における半径比が $1 / 2$ の時の波数と $\gamma R a$ の関係を示す. 波数 が 5 とき, 臨界值 94233 をとる。

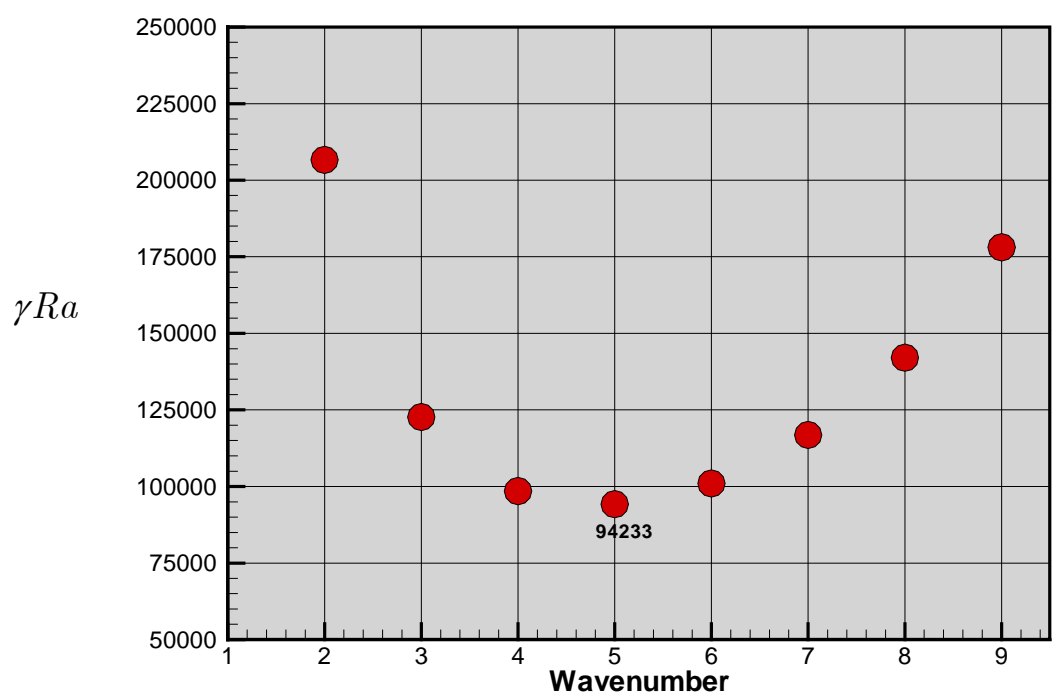

Fig. 2 The relationship between the azimuthal wavenumber and the neutral values of $\gamma R a$ for $\eta=1 / 2$

表 1 は, 線形安定性解析で得られた臨界值のまとめを示す. 外円筒に対する内円筒の半径比を種々変 えて解析を行った。軸対称解析では，ここでもNewton法により臨界波数 $k_{\mathrm{c}}$ 自動的に探索した。一方， 平面極解析では, 最小の臨界值 $\gamma a$ をとる整数值を臨界波数 $n_{\mathrm{c}}$ とした。半径比が同じ解析条件では, 平面 極解析で得られる臨界值が軸対称解析のそれよりも低く, その傾向は半径比が小さいほど顕著であるこ とから, 半径比が小さい場合は, 周方向に波数を持つ流れ場や温度場になることが予測できる. 半径比 が大きくなると，両解析による臨界值は互いに近くなってくるので，軸方向にも波数を持つようになる と予想される。

軸対称解析における臨界波数は, 半径比が増加するにつれて, 平板間のRayleigh-Bénard対流における 臨界波数 3.116 に近づいていくのがわかる. 一方で平面極解析における臨界波数は, 平均半径に円周率 を掛けた值に一番近い整数值であることがわかる. 臨界の $\gamma R a$ 值は, 平板間のRayleigh-Bénard対流の $R a_{\mathrm{c}}=$ 1707.8 とは異なり, 半径比が増加するにつれて著しく大きくなる傾向が見て取れる. これは半径比が 1 に近づくと, 電流位置（中心軸）からの距離が大きくなるのが原因であり，対流発生にはそれだけ強い 電流が必要とされることからわかる.あるいは円筒間の隙間が狭くなる場合に対応するとも見なされる. 後ほど, この $\gamma R a$ 值ではなく, 磁気レイリー数 $\left(R a_{\mathrm{m}}\right)$ を導入し考察する.

Table 1 Critical values obtained by the linear stability analyses

\begin{tabular}{|c|c|c|c|c|c|c|}
\hline & \multicolumn{3}{|c|}{ Axisymmetric analysis } & \multicolumn{3}{c|}{ Plane polar analysis } \\
\hline$\eta$ & $k_{\mathrm{c}}$ & $\gamma R a_{\mathrm{c}}$ & $R a_{m c}$ & $n_{\mathrm{c}}$ & $\gamma R a_{\mathrm{c}}$ & $R a_{m c}$ \\
\hline $1 / 3$ & 3.180 & $2.895 \times 10^{4}$ & 1466 & 3 & $2.327 \times 10^{4}$ & 1117 \\
\hline $1 / 2$ & 3.143 & $1.068 \times 10^{5}$ & 1601 & 5 & $9.423 \times 10^{4}$ & 1414 \\
\hline $2 / 3$ & 3.125 & $5.151 \times 10^{5}$ & 1669 & 8 & $4.813 \times 10^{5}$ & 1560 \\
\hline $3 / 4$ & 3.121 & $1.429 \times 10^{6}$ & 1687 & 11 & $1.365 \times 10^{6}$ & 1611 \\
\hline $5 / 6$ & 3.118 & $5.583 \times 10^{6}$ & 1699 & 17 & $5.432 \times 10^{6}$ & 1653 \\
\hline $10 / 11$ & 3.117 & $3.897 \times 10^{7}$ & 1705 & 33 & $3.842 \times 10^{7}$ & 1680 \\
\hline $19 / 20$ & 3.116 & $2.499 \times 10^{8}$ & 1707 & 61 & $2.480 \times 10^{8}$ & 1693 \\
\hline
\end{tabular}




\section{5. 数值解析}

\section{$5 \cdot 1$ 無次元方程式と解析手法}

式(13)-(17)を次のように無次元化した.

$$
\begin{aligned}
& \frac{\partial U}{\partial \tau}+U \frac{\partial U}{\partial R}+\frac{V}{R} \frac{\partial U}{\partial \theta}-\frac{V^{2}}{R}+W \frac{\partial U}{\partial Z}=-\frac{\partial P}{\partial R}+\frac{\gamma R a \cdot \operatorname{Pr}}{2 \pi^{2}} \frac{\Theta}{R^{3}}+\operatorname{Pr}\left(\frac{\partial^{2} U}{\partial R^{2}}+\frac{1}{R} \frac{\partial U}{\partial R}-\frac{U}{R^{2}}+\frac{1}{R^{2}} \frac{\partial^{2} U}{\partial \theta^{2}}-\frac{2}{R^{2}} \frac{\partial V}{\partial \theta}+\frac{\partial^{2} U}{\partial Z^{2}}\right) \\
& \frac{\partial V}{\partial \tau}+U \frac{\partial V}{\partial R}+\frac{V}{R} \frac{\partial V}{\partial \theta}+\frac{U V}{R}+W \frac{\partial V}{\partial Z}=-\frac{1}{R} \frac{\partial P}{\partial \theta}+\operatorname{Pr}\left(\frac{\partial^{2} V}{\partial R^{2}}+\frac{1}{R} \frac{\partial V}{\partial R}-\frac{V}{R^{2}}+\frac{1}{R^{2}} \frac{\partial^{2} V}{\partial \theta^{2}}+\frac{2}{R^{2}} \frac{\partial U}{\partial \theta}+\frac{\partial^{2} V}{\partial Z^{2}}\right) \\
& \frac{\partial W}{\partial \tau}+U \frac{\partial W}{\partial R}+\frac{V}{R} \frac{\partial W}{\partial \theta}+W \frac{\partial W}{\partial Z}=-\frac{\partial P}{\partial Z}+\operatorname{Pr}\left(\frac{\partial^{2} W}{\partial R^{2}}+\frac{1}{R} \frac{\partial W}{\partial R}+\frac{1}{R^{2}} \frac{\partial^{2} W}{\partial \theta^{2}}+\frac{\partial^{2} W}{\partial Z^{2}}\right) \\
& \frac{\partial U}{\partial R}+\frac{U}{R}+\frac{1}{R} \frac{\partial V}{\partial \theta}+\frac{\partial W}{\partial Z}=0 \\
& \frac{\partial \Theta}{\partial \tau}+U \frac{\partial \Theta}{\partial R}+\frac{V}{R} \frac{\partial \Theta}{\partial \theta}+W \frac{\partial \Theta}{\partial Z}=\left(\frac{\partial^{2} \Theta}{\partial R^{2}}+\frac{1}{R} \frac{\partial \Theta}{\partial R}+\frac{1}{R^{2}} \frac{\partial^{2} \Theta}{\partial \theta^{2}}+\frac{\partial^{2} \Theta}{\partial Z^{2}}\right)
\end{aligned}
$$

無次元数は $\gamma R a$ に加えて, 非線形項があるため $P r$ も現れる. 無次元の変数および無次元数は以下のよ うに定義した。

$$
\begin{aligned}
& \tau=\frac{t}{\left(r_{2}-r_{1}\right)^{2} / \alpha}, R=\frac{r}{r_{2}-r_{1}}, Z=\frac{z}{r_{2}-r_{1}}, U=\frac{u}{\alpha /\left(r_{2}-r_{1}\right)}, V=\frac{v}{\alpha /\left(r_{2}-r_{1}\right)}, W=\frac{w}{\alpha /\left(r_{2}-r_{1}\right)}, P=\frac{p}{\rho \alpha^{2} /\left(r_{2}-r_{1}\right)^{2}}, \\
& \Theta=\frac{T-T_{0}}{T_{1}-T_{2}}, \operatorname{Pr}=\frac{v}{\alpha}, \gamma R a=\frac{\chi_{0} \mu_{m} i_{c}^{2} \beta\left(T_{1}-T_{2}\right)}{\alpha v}, \eta=\frac{r_{1}}{r_{2}}, A=\frac{z_{0}}{r_{2}-r_{1}}, R_{1}=\frac{r_{1}}{r_{2}-r_{1}}, R_{2}=\frac{r_{2}}{r_{2}-r_{1}}
\end{aligned}
$$

初期条件は，流体静止で熱伝導状態としている.

$$
U=V=W=P=0, \quad \Theta=\frac{\ln \left(R / R_{2}\right)+\ln \left(R / R_{1}\right)}{2 \ln \eta} \text { for } \tau \leq 0
$$

境界条件は, すべての壁面上で滑り無しとし, 内壁で等温加熱，外壁で等温冷却とし，上下壁では断熱 とした.

$$
\begin{array}{ll}
U=V=W=0, & \Theta=0.5 \quad \text { at } R=R_{1} \\
U=V=W=0, & \Theta=-0.5 \quad \text { at } R=R_{2} \\
U=V=W=0, & \partial \Theta / \partial Z=0 \quad \text { at } Z=0, A
\end{array}
$$

上記の支配方程式ならびに初期条件と境界条件は, 円筒座標系にて差分法を用いて数值的に解いた。格 子分割には等間隔のスタッガードメッシュを採用し，圧力の解法には，連続の式を満足させる HSMAC (Highly Simplified Marker And Cell) 法を用いた.移流項には三次精度の風上差分法の一つであるUTOPIA (Uniformly Third-Order Polynomial Interpolation Algorithm) スキームを用いた.

\section{$5 \cdot 2$ 軸対称解析結果}

図 3 には容器の高さが隙間幅の 4 倍の場合に得られた計算結果（幾つかの時刻における温度分布）を 示す．容器の上端と下端は滑り無しの固体壁で断熱条件としている．なお計算条件は $\eta=10 / 11, \gamma R a=5$ $\times 10^{7}$ の場合を示す。線形安定性解析で得られる臨界值よりも高い值（1.3 倍程度）で計算しているので 対流が発生し，最終的に定常解を得ている。表 1 に示されるように，軸対称解析の臨界值は平面極解析 のそれよりも高く，実際に起こり得る現象ではないと思われるが，線形と非線形の両解析を比較すると いう意味で検討した。 


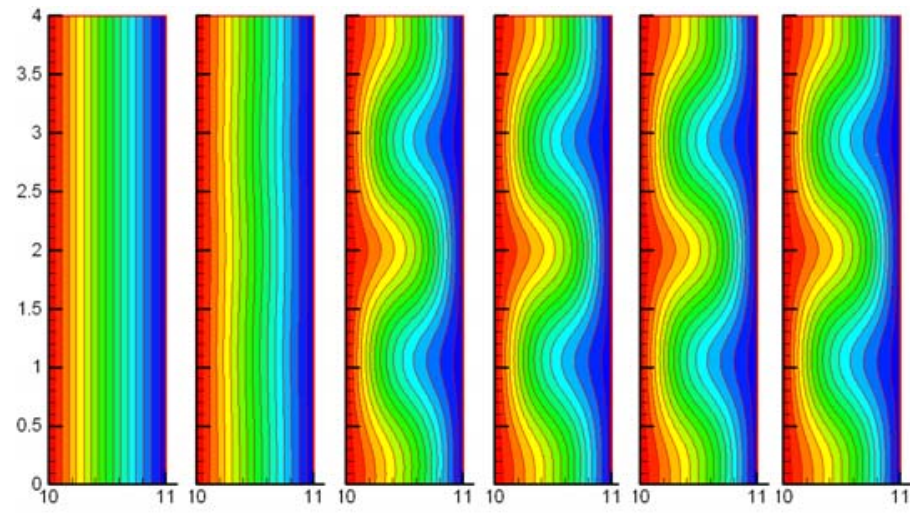

$\tau=0.04, \quad 0.60, \quad 0.80, \quad 1.60, \quad 2.00, \quad 20.0$

Fig. 3 Temperature field for various time instants for $\eta=10 / 11, \gamma R a=5 \times 10^{7}, A=4$ and $\operatorname{Pr}=0.7$

\section{$5 \cdot 3$ 平面極座標解析結果}

図 4 (a) には, 線形安定性解析により得られる臨界值の約 2 倍である $\gamma R a=2 \times 10^{5}$ における速度場, 温 度場，および圧力場の定常状態の可視化を示寸．Pr数は 0.7 とし，半径比は $1 / 2$ である. 本計算により 得られた周方向波数は 5 であり，線形安定性解析で得られる波数に一致している．また，(b) には半径 比が $3 / 4$ で $\gamma R a=1.6 \times 10^{6}$ (臨界值の約 1.2 倍）における速度場, 温度場, および圧力場の可視化も示す. この場合, 周方向波数は 11 であり, これも線形安定性解析で得られる波数に一致している.

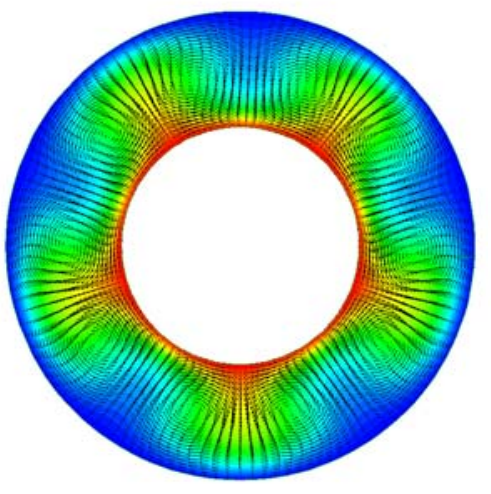

Temperature

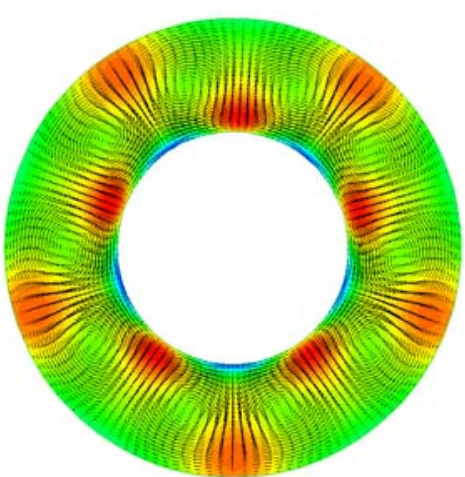

Pressure

(a) $\eta=1 / 2, \quad \gamma R a=2 \times 10^{5}$

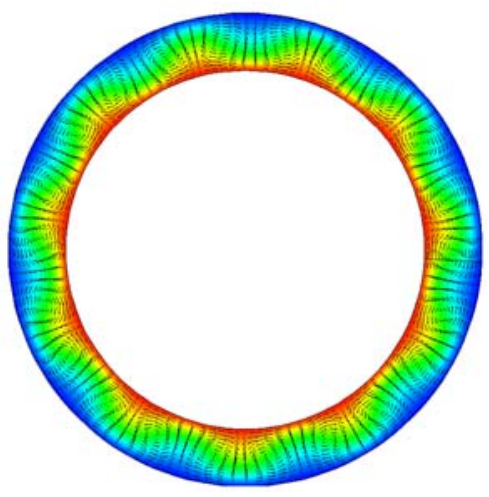

Temperature

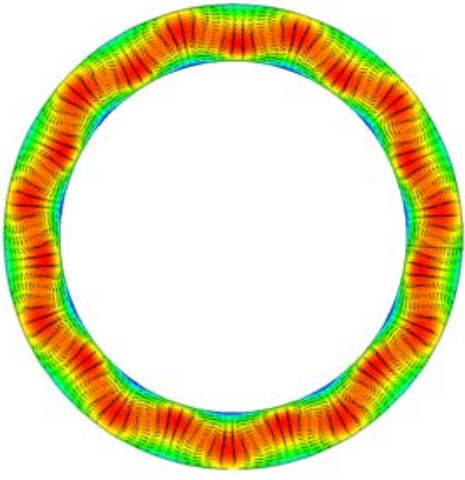

Pressure

(b) $\eta=3 / 4, \quad \gamma R a=1.6 \times 10^{6}$

Fig. 4 Velocity vectors, temperature field and pressure field obtained by the polar coordinate system analyses for a steady state at $\operatorname{Pr}=0.7$ 


\section{$5 \cdot 4$ 三次元解析結果}

図 5 (a) は，三次元解析による温度分布を示す．境界条件，半径比および容器高さは，図 3 (a) と共通 である. 臨界值の 2 倍程度までの大きさでは定常解が得られた。軸方向には殆ど変化の無い温度場とな っているのがわかる。平均 $\mathrm{Nu}$ 数は，それぞれ，1.888, 2.145, 2.517 となった. 図 5 (b) は，臨界值の 4 倍程度の場合であり, 定常解は得られなかったので, 任意の 3 つの時刻における温度分布を示す. 計算 開始まもなく $(\tau=0.48)$ ，周方向に波数 5 を持つ対流が発生し，それは平面極座標解析の結果に似てい るが, 臨界值の約 4 倍とやや大きい為か, 時間が経過していくと, 波の分裂・合体を繰り返寸複雑な振 動を呈していくことがわかった.

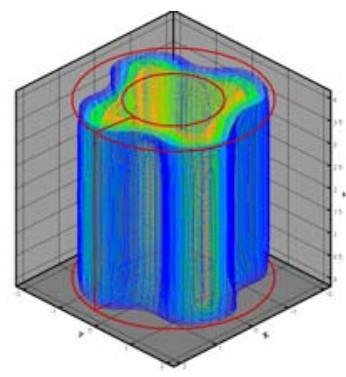

$$
\gamma R a=1.1 \times 10^{5}
$$

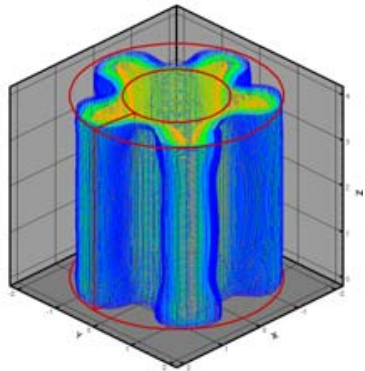

$\tau=0.48$

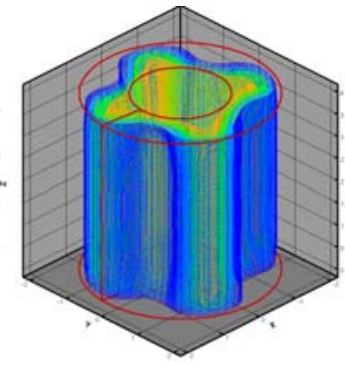

$1.4 \times 10^{5}$

(a) Steady solutions

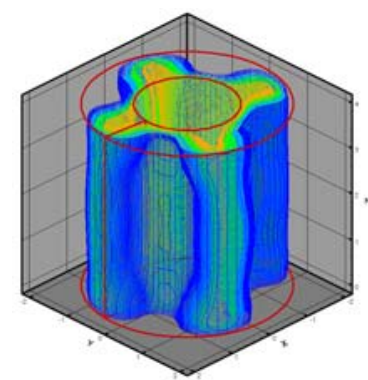

4.00

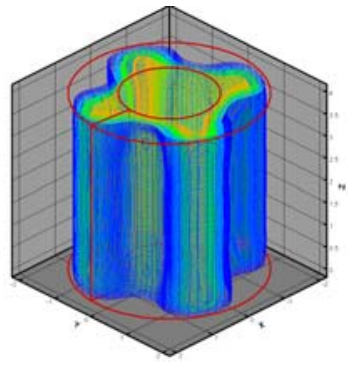

$2.0 \times 10^{5}$

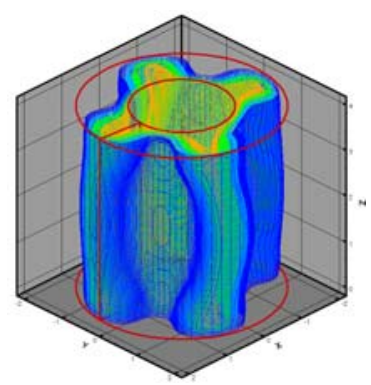

8.00

(b) Unsteady solution for $\gamma R a=4.0 \times 10^{5}$

Fig. 5 A perspective view of temperature field for $\eta=1 / 2, A=4$ and $\operatorname{Pr}=0.7$

\section{6. 考察}

\section{6・1 磁気レイリー数について}

磁気レイリー数を次のように定義する.

$$
R a_{m}=\frac{g_{m} \beta\left(T_{1}-T_{2}\right)\left(r_{2}-r_{1}\right)^{3}}{\alpha v}
$$

ここで, $g_{\mathrm{m}}$ は磁気力による加速度を表す. 次に磁気浮力と重力浮力の比を考える. 磁気浮力は半径の関 数であるが，ここでは以下に示すように相加平均半径を用いて評価するとする.

$$
\frac{\text { Magnetic force }}{\text { Gravitational force }}=\frac{\left|\rho_{0} \chi_{0} \beta_{0}\left(T-T_{0}\right) \frac{\mu_{m} i_{c}^{2}}{2 \pi^{2}} \frac{1}{r^{3}}\right|_{r=\left(r_{1}+r_{2}\right) / 2}}{\left|\rho_{0} g \beta_{0}\left(T-T_{0}\right)\right|}=\frac{\left|\chi_{0}\right| \mu_{m} i_{c}^{2}}{2 \pi^{2} g}\left(\frac{1}{r^{3}}\right)_{r=\left(r_{1}+r_{2}\right) / 2}
$$

したがって， $g_{m}$ は以下のように与えられる. 


$$
g_{m}=\frac{\left|\chi_{0}\right| \mu_{m} i_{c}^{2}}{2 \pi^{2}}\left(\frac{1}{r^{3}}\right)_{r=\left(r_{1}+r_{2}\right) / 2}
$$

結局, 磁気レイリー数は,

$$
R a_{m}=\frac{g_{m} \beta\left(T_{1}-T_{2}\right)\left(r_{2}-r_{1}\right)^{3}}{\alpha v}=\frac{\beta\left(T_{1}-T_{2}\right)}{\alpha v} \frac{\chi_{0} \mu_{m} i_{c}^{2}}{2 \pi^{2}}\left\{\frac{\left(r_{2}-r_{1}\right)^{3}}{r^{3}}\right\}_{r=\left(r_{1}+r_{2}\right) / 2}=\frac{\gamma R a}{2 \pi^{2}}\left(\frac{1}{R^{3}}\right)_{R=\left(R_{1}+R_{2}\right) / 2}
$$

となる。これは，平板間のレイリー・ベナール対流に現れる次の 2 式

$$
\begin{aligned}
& \left(\frac{d^{2}}{d Z^{2}}-k^{2}\right)^{2} \tilde{W}=k^{2} R a \tilde{\Theta} \\
& \left(\frac{d^{2}}{d Z^{2}}-k^{2}\right) \tilde{\Theta}=-\tilde{W}
\end{aligned}
$$

を(35), (36) と見比べれば, 半径比が 1 に近づくとき, 容器曲率の影響が無くなり妥当な結果であること がわかる. 前述の表 1 に磁気レイリー数の臨界值をまとめた. 半径比が 1 に近づくと, 両面が滑り無し でそれぞれ異なる一定温度に保たれた時のレイリー・ベナール対流の臨界レイリー数 $1707.8 に$ に近づくの が見て取れる。

\section{$6 \cdot 2$ 有次元換算例}

加熱面と冷却面の温度差を $10 \mathrm{~K} ， 2$ 月筒間の隙間幅を $3,10 \mathrm{~mm}$ と仮定したとき, 理想気体と見なされ る常温常圧の空気の物性值 (基準温度 $T_{0}=293 \mathrm{~K}$, 磁化率 $\chi_{0}=3.24 \times 10^{-7} \mathrm{~m}^{3} / \mathrm{kg}$, 透磁率 $\mu_{\mathrm{m}}=4 \pi \times 10^{-7} \mathrm{H} / \mathrm{m}$, 温度伝導率 $\alpha=2.16 \times 10^{-5} \mathrm{~m}^{2} / \mathrm{s}$, 動粘度 $v=1.51 \times 10^{-5} \mathrm{~m}^{2} / \mathrm{s}$ ） を用いて, 有次元換算された内壁における磁 束密度を求めるものとする. 例えば, $\gamma R a=10^{5}$, 半径比 0.5 , 隙間幅 $3 \mathrm{~mm}$ の場合, 磁束密度の参照值は (38)式において,

$$
i_{c}=\frac{2 \pi\left(r_{2}-r_{1}\right)}{\mu_{m}} b_{0}
$$

として, 以下のようにして求まる.

$$
b_{0}^{2}=\frac{\mu_{m} \alpha v}{4 \pi^{2} \chi_{0} \beta} \frac{\gamma R a}{\left(T_{1}-T_{2}\right)\left(r_{2}-r_{1}\right)^{2}}=\frac{\left(4 \pi \times 10^{-7}\right)\left(2.16 \times 10^{-5}\right)\left(1.51 \times 10^{-5}\right)}{\left(4 \pi^{2}\right)\left(3.24 \times 10^{-7}\right)(1 / 293)} \frac{\left(10^{5}\right)}{(10)(0.06-0.03)^{2}}=0.104
$$

これより，内壁面における磁束密度は，

$$
\left|\vec{b}_{1}\right|=b_{0}\left|\vec{B}_{1}\right|=\frac{b_{0}}{R_{1}} \cong \frac{0.323}{1}=0.323
$$

となり， 0.3 テスラ程度の磁束密度は，十分に現実的な值であることがわかる. 表 2 に幾つかの換算例 をまとめる。

Table 2 Conversion into dimensional values for the temperature difference $10 \mathrm{~K}$

\begin{tabular}{|l|c|c|c|c|c|}
\hline \multicolumn{2}{|c|}{} & \multicolumn{2}{c|}{$\gamma R a=10^{5}$} & \multicolumn{2}{c|}{$\gamma R a=10^{6}$} \\
\hline \multirow{3}{*}{$\eta=1 / 2$} & Gap [mm] & 3 & 10 & 3 & 10 \\
\cline { 2 - 5 } & $\begin{array}{c}\text { Magnetic flux density at the } \\
\text { inner wall [mT] }\end{array}$ & 323 & 97 & 1021 & 307 \\
\hline \multirow{3}{*}{$\eta=3 / 4$} & Gap [mm] & 3 & 10 & 3 & 10 \\
\cline { 2 - 5 } & $\begin{array}{c}\text { Magnetic flux density at the } \\
\text { inner wall [mT] }\end{array}$ & 108 & 32 & 340 & 102 \\
\hline
\end{tabular}




\section{7. 結 語}

同軸二重円間内における空気の磁気熱対流の線形安定性解析ならびに数值解析を行い, 次の知見を得 た.

1. 内円筒加熱で外円筒冷却の場合, 磁気浮力のため不安定となり, ある臨界の磁場以上で対流が発生 する．そのときの磁場強度は， 0.3 テスラ程度であり十分に実用範囲である.

2. 平面極擋乱を与えた線形安定性解析の臨界值は, 軸対称のそれよりも小さいので, 実際には周方向 に波数を持つ流れ場になることが予測され，三次元数值解析の結果はそれを示唆している.

3. 半径比が 1 に近づくにつれて，等価レイリー数は 1707.8 の臨界值に近づく.

\section{文献}

(1) Ikezoe, Y., Hirota, N., Nakagawa, J. and Kitazawa, K., "Making water levitate", Nature Vol. 393, (1998), pp.749-750.

(2) Chandrasekar, S., Hydrodynamic and Hydromagnetic Stability, Dover, (1961).

(3) 日向野三雄, 液体層の熱的不安定性（第一報, 界面張力による場合）, 日本機械学会論文集 B 編, Vol. 47, No. 413 (1981), pp. 105-112.

（4）日向野三雄，液体層の熱的不安定性（第二報，浮力による場合）, 日本機械学会論文集 B 編，Vol. 47, No. 413 (1981), pp. 113-120.

（5）日向野三雄, 液体層の熱的不安定性（第三報, 浮力と界面張力の共存する場合）, 日本機械学会論 文集 B 編，Vol. 47, No. 420 (1981), pp. 1571-1577.

(6) Tagawa, T., Shigemitsu, R. and Ozoe, H., "Magnetizing force modeled and numerically solved for natural convection of air in a cubic enclosure: effect of the direction of the magnetic field", Int. J. Heat Mass Transfer, Vol. 45, (2002), pp. 267-277.

(7) Bai, B., Yabe, A., Qi, J. and Wakayama, N.I., "Quantitative analysis of air caused by the magnetic-fluid coupling", AIAA Journal, Vol. 37, No. 12, (1999), pp. 1538-1543. 